\section{Investigation of children with enuresis and urinary tract infections}

Sir,

I wonder if other paediatricians will join me in deploring the invasive investigations perpetrated on children with urinary tract infections.

Two recent papers in the Archives, from Leeds ${ }^{1}$ and Melbourne, ${ }^{2}$ report that after a urinary tract infection micturating cystourethrograms were performed on almost all, and intravenous urograms on many, of the children, during studies on daytime enuresis and urinary nitrite, respectively.

It is over 10 years since we showed in Derby that it is possible to exclude severe reflux (the main abnormality found on a micturating cystourethrogram) in $90 \%$ of cases by examining the intravenous urogram carefully, ${ }^{3}$ and last year we showed that ultrasonography is almost as reliable as intravenous urography in detecting important renal tract abnormalities. ${ }^{4}$ Micturating cystography is a potentially dangerous, ${ }^{5}$ and extremely unpleasant investigation (ask the children) and an intravenous urogram little better. In most children they can reliably be replaced by ultrasonography as the first investigation.

I believe that paediatricians have an obligation to their patients to protect them from these painful and usually unnecessary tests.

\section{References \\ 1 Halliday S. Meadow SR, Berg I. Successful management of daytime enuresis using alarm procedures: a randomly controlled trial. Arch Dis Child 1987:62:132-7. \\ 2 Powell HR. McCredie DA. Ritchic MA. Urinary nitrite in symptomatic and asymptomatic urinary infection. Arch Dis Child 1987:62:138-40. \\ ${ }^{3}$ Moncricff MW, Whitelaw R. Value of cystography in urinary tract infections. Arch Dis Child 1976;51:893-5. \\ + Lindsell D. Moncrieff MW. Comparison of ultrasound examin- ation and intravenous urography after a urinary tract infection. Arch Dis Child 1986;61:81-2. \\ 5 McAlister WH. Cicciarelli A. Shackelford GD. Complications associated with cystography in children. Radiology 1974:111 $167-72$.}

M W MONCRIFFF John Radcliffe Hospital, Headington. Oxford $O X 39 D U$

\section{Professor Meadow comments:}

The children included in the Leeds study had been investigated in different units at various times in the past. I am sure that if their investigation had been more recent ultrasonography of the renal tract combined with straight abdominal $x$-ray would have been the prime investigation for many of the children.

I share some but not all of Dr Moncrieff's enthusiasm for ultrasonography; it does have its limitations. Ultrasound is much better for visualisation of the upper urinary tract than the lower, and inadequate for detecting urethral lesions. It depends on a committed and skilled operator. Moreover, because there are not yet agreed standard procedures for ultrasonography, one does not have comparable sets of hard pictures for others to study and discuss at $x$-ray meetings and joint clinics. Until such standard sets of pictures are available and clinicians have learnt to interpret them, ultrasonography is likely to be associated with more misinterpretations than a standard intravenous urogram.

Dr Powell comments:

Dr Moncrieff's remarks are largely irrelevant to the main purpose of our report which concerned the effects of urinary frequency on the nitrite dip strip test. His comments do, however, illustrate the divergence of opinion on the need for, and best methods of, investigation after diagnosis of urinary tract infection. With the accumulating evidence that urinary reflux only rarely leads to new renal damage in older children we would now agree with Dr Moncrieff that voiding cystography is usually unnecessary in children over 5 years old and that good quality ultrasound, if available, can replace the intravenous urogram. The intravenous urogram is generally performed well, even in small centres, which frequently have difficulty providing good quality ultrasound examinations. Thus the choice of investigation depends on the quality of the organ imaging service locally available. At this hospital, we now recommend an ultrasound and cystogram on all patients under 5 years old with urinary tract infections and an ultrasound alone on older children.

\section{Diagnosis and management of urinary tract infection}

Sir,

I read with interest the recent article by Professor White and an earlier one by Dr Haycock, ${ }^{-}$about childhood urinary tract infection.

There is little disagreement about the limited need for a routine micturating cystourethrogram in older children with recurrent urinary tract infection. The procedure may introduce infection, is painful, and occasionally dangerous. ${ }^{3}$ I would therefore like to emphasise the importance of preand post micturition ultrasound examination in such cases.

In the last eight months we have seen four girls, aged 7 to 12 years, referred because of recurrent urinary tract infection in spite of continuous antibiotic prophylaxis. Ultrasound examinations and intravenous pyelograms were normal. Repeat ultrasound examinations, including pre- and post micturition examination showed incomplete emptying of the bladder that was subsequently confirmed by micturating cystourethrography. Cystoscopy showed minor degrees of outlet obstruction in two cases, severe trigonitis in one, and a poorly functioning atonic bladder in the remaining case.

In view of its widespread availability and non-invasive nature, children (particularly over 5 years old) with recurrent urinary tract infections should have routine preand post micturition ultrasound examinations. Similarly. a post micturition film after an intravenous pyelogram may be helpful. 